\title{
Porcine pancreatin as a source of salmonella infection in children with cystic fibrosis
}

\author{
A. LIPSON AND H. MEIKLE
}

From The Hospital for Sick Children, London

SUMMARY Contamination of a powdered preparation of pancreatin with Salmonella schwarzengrund and $S$. eimsbuettel resulted in the infection of at least $31 \%$ of one group of paediatric patients with cystic fibrosis. The pancreatin contained very small numbers of Salmonellae, the infecting dose in at least one child being less than 44 organisms. More stringent bacteriological standards are needed for pharmaceuticals and foods used by paediatric patients.

Many pharmaceutical products derived from animal sources may be contaminated with Salmonella organisms (Krugman and Ward, 1973), and human infection has been reported from the consumption of carmine dye (Lang et al., 1967), thyroid extract (Kallings et al., 1966), and pancreatin powder (Glencross, 1972). In August 1975, the Salmonella Reference Laboratory at the Central Public Health Laboratory drew attention to contamination of a porcine-derived pancreatin preparation with $S$. schwarzengrund and S. eimsbuettel (Rowe and Hall, 1975). In order to determine the prevalence of salmonellosis in patients taking pancreatin, children with cystic fibrosis (CF) were studied retrospectively from January 1971 to December 1975, and by a bacteriological survey in September and October 1975.

\section{Bacteriological survey of CF patients}

130 patients who were regularly attending the CF outpatient clinic during September and October Received 3 December 1976
1975 had a single rectal swab examined bacteriologically by inoculation onto deoxycholate citrate lactose sucrose (DCLS) agar, and into Selenite F, both selective media for Salmonellae organisms. S. schwarzengrund was isolated from 7 of these patients and $S$. enteritidis from one (Table 1). The 7 patients with $S$. schwarzengrund were taking the same brand of pancreatin implicated by the Salmonella Reference Laboratory; 6 in the powder form and 1 in tablet form. The patient from whom $S$. enteritidis was isolated was taking a different brand of pancreatin.

Three of the 8 patients had a course of antibiotics in the month preceding isolation of the organism, 2 with erythromycin and 1 with cloxacillin. Their average age was 5.5 years, ranging from 7 months to 12 years. There were 6 females and 2 males 2 patients were failing to thrive, a 6-year-old boy who died of respiratory failure soon afterwards, and a 12-year-old girl with biliary cirrhosis.

Forty-two of the 130 children were taking the same powder form of pancreatin, and 83 took tablets or capsules of pancreatin from the same manu-

Table 1 Clinical details of cystic fibrosis patients with salmonellosis, January 1971-August 1975

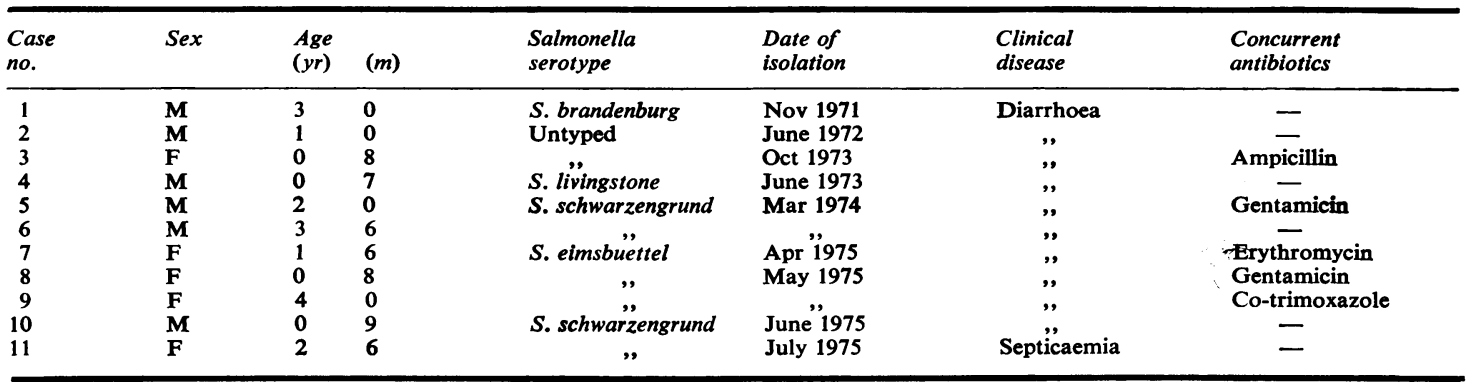


Table 2 Bacteriological survey by rectal swab of 130 children with cystic fibrosis-September to October 1975

\begin{tabular}{lll}
\hline $\begin{array}{l}\text { Type of preparation } \\
\text { consumed }\end{array}$ & $\begin{array}{l}\text { No. of } \\
\text { patients }\end{array}$ & Results \\
\hline $\begin{array}{l}\text { Pancrex powder } \\
\text { Pancrex tablets }\end{array}$ & 42 & $6-S$. schwarzengrund \\
Other preparations & 83 & $1-S$. schwarzengrund \\
\hline
\end{tabular}

facturer as the powder form. Pancreatin from other sources was used by 5 children (Table 2).

\section{Bacteriological examination of pancreatin}

The current hospital stock of pancreatin was screened for contamination in September 1975 by the method described by Glencross (1972). $10 \mathrm{~g}$ were sampled from each container, tablets and granules being ground to powder form and capsules opened before culture. $S$. schwarzengrund was isolated from six $250 \mathrm{~g}$ containers of two batches of the powder form of the Pancrex brand. No sample from these two batches failed to grow the organism. Salmonellae were not isolated from the several other batches screened at the same time. Three of the contaminated samples were from the opened containers of patients with proven infection with the same salmonella serotype, one was from a patient with no history of diarrhoea and a negative rectal swab, and two were from unopened containers. No pathogen was isolated from current stocks of Pancrex tablets, granules, or capsules though other batches of these preparations have been found by other laboratories to be contaminated by $S$. eimsbuettel and S. schwarzengrund (Central Public Health Laboratory, 1975).

The preparation consumed by one infant was examined in more detail in an attempt to establish an infecting dose of Salmonella. This child, aged 9 months, was newly diagnosed and developed symptoms of enteritis 2 weeks after starting pancreatin. No antibiotics were given. The number of Salmonellae was less than 2 per $\mathrm{g}$ in a $100 \mathrm{~g}$ sample. He was taking $0.7 \mathrm{~g}$ 6-hourly with feeds, this dose being doubled 36 hours before the onset of enteritis.
His dosage of organisms was therefore less than 22 organisms per day initially, increasing to less than 44 organisms per day in the 36 hours before presentation. Assuming that the infecting dose was not cumulative over 24 hours, less than 44 organisms can be estimated as the infecting dose in this patient.

Other brands of pancreatin including the preparation which was consumed by the patient from whom $S$. enteritidis was isolated in the prospective survey were also screened and found to contain no Salmonellae.

The practice of preparing food with added pancreatin some time before consumption, which might cause bacterial multiplication, was investigated by indirectly questioning patients at their routine clinic visit. Of the infected patients surveyed all added pancreatin to food immediately before each meal.

\section{Retrospective survey of salmonellosis in CF}

A salmonella infection had been diagnosed in 11 patients with CF at this hospital between January 1971 and December 1975. 4 patients with $S$. schwarzengrund and 3 with $S$. eimsbuettel were identified (Table 1). They were all taking the same brand of the powder form of pancreatin in a dose of 1-2 teaspoons per meal and were diagnosed in 1974 and 1975. At least 1 (Case 1 ) of the 4 remaining cases could be attributed to contaminated pancreatin powder. This child had an $S$. brandenburg enteritis in November 1971, at the same time that Glencross (1972) reported contamination of the same powder form of pancreatin with $S$. brandenburg, $S$. agona, and $S$. anatum. Other patients infected with the same serotypes were also surveyed (Table 3). Those cross-infected with $S$. eimsbuettel were family members of an index case. Those cross-infected with $S$. schwarzengrund were other hospital patients resident in the same wards.

The patients from whom $S$. schwarzengrund and S. eimsbuettel were isolated are described in Table 1. No patient of this group was failing to thrive, though 2 (Cases 2, 5) were acutely unwell with

Table 3 Salmonella isolations-5 serotypes only from January 1971 to August 1975

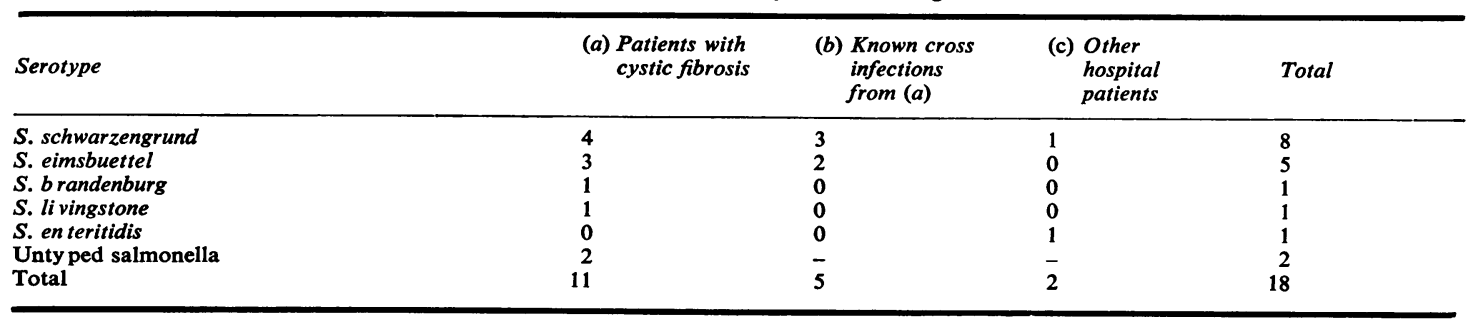


pneumonia at the time of diagnosis. Cases 7 and 9 were receiving antibiotics prophylactically. One child had a $S$. schwarzengrund enteritis after receiving powdered pancreatin for a presumptive diagnosis of CF which was subsequently disproved (Table $3, \mathrm{c}$ ).

\section{Discussion}

Thirteen of $42(31 \%)$ CF patients receiving the pancreatin powder Pancrex in 1974 and 1975 were infected with $S$. schwarzengrund or $S$. eimsbuettel. A further two infections could be definitely associated with this preparation, the case of $S$. brandenburg enteritis in November 1971 (Table 1) and the child described earlier who had pancreatin administered inappropriately. The rate of infection was probably higher as it could not be established if each of the patients from whom Salmonella was not isolated had in fact consumed a contaminated preparation and survey by single rectal swab (Drachman, 1974) a month or more after exposure to infection must carry a false-negative rate. It is known that Salmonellae survive for long periods at room temperature when contaminating a dry powder preparation (Prost and Rieman, 1967). The pancreatin powder described in this study was heat-treated at $115^{\circ} \mathrm{C}$ for 5-10 minutes. Possible factors that could determine contamination include resistance of specific serotypes to decontamination procedures, defective control measures, or contamination during storage.

$S$. schwarzengrund and $S$. eimsbuettel used to be isolated rarely in the United Kingdom. From January 1973 to August 1975, the Salmonella Reference Laboratory has identified $S$. schwarzengrund 47 times and in 10 instances the patients were receiving pancreatic supplementation. S. eimsbuettel was identified 31 times in this period and in 15 instances the patients were receiving pancreatic supplementation (Rowe and Hall, 1975). From August 1975 to June 1976 a further 17 children receiving pancreatic supplementation have been reported by the Salmonella Reference Laboratory, 14 with $S$. schwarzengrund and 3 with $S$. eimsbuettel. One child aged 9 months died of a fulminating $S$. schwarzengrund enteritis one week after starting pancreatin. The incidence of $S$. schwarzengrund infections from all sources has since shown a large increase, this serotype being now the sixth most common isolated from humans in the United Kingdom (Central Public Health Laboratory, 1976). Account must be taken in these figures for cross-infection from index cases, as 5 cases were seen in this survey (Table 3).

All known contaminated material was imported from a single factory in the Netherlands, which also supplies other manufacturers of pancreatin in Europe. All pancreatin is of porcine derivation due to the great potency of this source. The proportion of imported material to the manufacturers' United Kingdom sources over the period described had been variable and dependent on the availability and quality of the raw material (F. P. Diggins, personal communication). Both the implicated serotypes are relatively common in the Netherlands, particularly $S$. eimsbuettel, and are isolated in man, abattoirs, meat shops, and animal feeds (Guinée and Valkenburg, 1975).

The principal Salmonella reservoir is the vertebrate intestinal tract, and pigs form a pool of symptomless infection in domesticated animals. The organisms reside principally in the bowel and the mesenteric lymph nodes, but can occur in the liver, spleen, and muscle. The incidence of infection varies from $4 \%$ to $22 \%$ (Prost and Rieman, 1967; Lancet, 1972), the variables including the care taken in feeding the animals uncontaminated meal, stress of travel to market, the herding of animals into barns and abbatoir lairs for prolonged periods, which can increase cross-infection, and abbatoir technique because cross-contamination can occur from contact with dirty dehairing machines, eviscerating tables, and cutting knives. Emergency slaughter can disseminate the organisms from the mesenteric nodes (Bowmer, 1964; Prost and Rieman, 1967; Christie, 1974).

Less than 50 organisms infected one patient and this number probably represents a reasonable estimate in all the patients who consumed the contaminated powder preparation as the dose in each was similar. In healthy adult humans (McCullough and Eisele, 1951a, b, c; Hornick et al., 1970), and animals (Bohnhoff and Miller, 1962), the dose of Salmonella required to cause infection is of the order of $10^{5}$ to $10^{6}$ organisms. $10^{4}$ organisms have caused infection from contaminated carmine dye given for diagnostic purposes (Lang et al., 1967) and contaminated imitation ice cream (Armstrong et al., 1970). The age, condition, and whether antibiotics had been previously given to affected patients were not stated in these reports. The lowest quantitated infecting dose in man before this report was $10^{3} S$. eastbourne organisms from contaminated chocolate (Craven et al., 1975). Malnutrition (Gordon and Scrimshaw, 1970), a disease of the alimentary tract in man, including pancreatic dysfunction (Hook, 1961), and broad spectrum antibiotic treatment in animals (Bohnhoff and Miller, 1962) can predispose to infection from a substantially smaller number of organisms. Most patients with CF have many courses of broad spectrum antibiotics which can alter the bacterial flora of the intestinal tract and may increase susceptibility to a low dose infection. 11 of the 13 infected children were below 
the age of 4 and this indicates the younger age group who consume powder rather than tablets of pancreatin. However, the average age of 1.5 years in the symptomatic group (Table 1) confirms the common clinical observation that the attack rate for clinical infection is higher in the very young, possibly due to smaller infecting doses.

The rarity of the serotypes implicated in these cases was the only reason that contamination was suspected. Ascertainment of infective diarrhoea in a condition which has diarrhoea as a symptom would be low, so that increased surveillance is necessary to define the size of the problem. The infection in Cases 2, 3, and 4 (Table 1) must be suspected as caused by contaminated pancreatin.

Increased surveillance by the manufacturer now requires that four $25 \mathrm{~g}$ lots from each batch of pancreatin are screened for contamination. Before this, single $25 \mathrm{~g}$ lots were tested, imported batches being accompanied by a certificate claiming freedom from Salmonella. Gamma irradiation will be used in the near future to ensure sterility of their product, which is distributed mainly in the United Kingdom.

The small number of organisms infecting these children indicates that the present official recommendation of no more than one organism in $10 \mathrm{~g}$ (British Pharmacopoeia, 1973) needs to be revised. A joint FAO/WHO food standards programme for infants and children has recommended that no more than one Salmonella organism per $30 \mathrm{~g}$ be cultured as a bacteriological standard for foods and pharmaceuticals (FAO/WHO, 1976). The results of this survey support a more stringent standard.

We thank Dr. W. C. Marshall, Dr. A. P. Norman, and Mr. W. J. Hamilton for their encouragement.

\section{References}

Armstrong, R. W., Fodor, T., Curlin, G. T., Cohen, A. B., Morris, G. K., Martin, W. T., and Feldman, J. (1970). Epidemic Salmonella gastroenteritis due to contaminated imitation ice cream. American Journal of Epidemiology, 91, 300-307.

Bohnhoff, M., and Miller, C. P. (1962). Enhanced susceptibility to Salmonella infection in streptomycin-treated mice. Journal of Infectious Diseases, 111, 117-127.

Bowmer, E. J. (1964). Challenge of salmonellosis: major public health problem. American Journal of the Medical Sciences, 247, 467-501.

British Pharmacopoeia (1973). No. 340. HMSO, London.
Central Public Health Laboratory (1975). Communicable Disease Report, 1975, No. 44. Epidemiological Research Laboratory, London.

Central Public Health Laboratory (1976). Communicable Disease Report, 1976, No. 26. Epidemiological Research Laboratory, London.

Christie, A. B. (1974). Infectious Diseases, p. 20. Churchill Livingstone, Edinburgh.

Craven, P. C., Mackel, B. C., Baine, W. B., and Barker, W. H. (1975). International outbreak of Salmonella Eastbourne infection traced to contaminated chocolate. Lancet, 1, 788-792.

Drachman, R. H. (1974). Acute infectious gastroenteritis. Pediatric Clinics of North America, 21, 711-737.

FAO/WHO (1976). Code of Hygienic Practice for Foods for Infants and Children. ALINORM 76/13A, Appendix V. FAO, Rome.

Glencross, E. J. G. (1972). Pancreatin as a source of hospitalacquired salmonellosis. British Medical Journal, 2, 376-378.

Gordon, J. E., and Scrimshaw, N. S. (1970). Infectious disease in the malnourished. Medical Clinics of North America, 54, 1495-1508.

Guinée, P. A. M., and Valkenburg, J. (1975). Salmonella isolations in the Netherlands, 1966-1973. Zentralblatt für Bakteriologie, Parasitenkunde, Infektionskrankheiten und Hygiene (I Abt. Originale A), 231, 97-107.

Hook, E. W. (1961). Salmonellosis: certain factors influencing the interaction of Salmonella and the human host. Bulletin of the New York Academy of Medicine, 37, 499-512.

Hornick, R. B., Greisman, S. E., Woodward, T. E., DuPont, H. L., Dawkins, A. T., and Snyder, M. J. (1970). Typhoid fever: pathogenesis and immunologic control. New England Journal of Medicine, 283, 686-691.

Kallings, L. O., Ringertz, O., and Silverstolpe, L. (1966). Microbiological contamination of medical preparations. Acta Pharmaceutica Suedica, 3, 219-228.

Krugman, S., and Ward, R. (1973). Infectious Disease of Children and Adults, 5th ed., p. 261. Mosby, St. Louis.

Lancet (1972). Pigs and disease, 1, 830.

Lang, D. J., KUNZ, L. J., Martin, A. R., Schroeder, S., and Thomson, L. A. (1967). Carmine as a source of nosocomial salmonellosis. New England Journal of Medicine, 276, 829-832.

McCullough, W. B., and Eisele, C. W. (1951a). Experimental human salmonellosis. I. Journal of Infectious Diseases, 88, 278-289.

McCullough, W. B., and Eisele, C. W. (1951b). Experimental human salmonellosis. III. Journal of Infectious Diseases, 89, 209-213.

McCullough, W. B., and Eisele, C. W. (1951c). Experimental human salmonellosis. IV. Journal of Infectious Diseases, 89, 259-265.

Prost, E., and Rieman, H. (1967). Food-borne salmonellosis. Annual Review of Microbiology, 21, 495-528.

Rowe, B., and Hall, M. L. M. (1975). Salmonella contamination of therapeutic pancreatin preparations. British Medical Journal, 4, 51.

Correspondence to Dr. A. H. Lipson, Royal Alexandra Hospital for Children, Camperdown, 2050 N.S.W., Australia. 